\title{
Forage fish abundance is a predictor of timing of breeding and hatching brood size in a coastal seabird
}

\author{
Svein-Håkon Lorentsen ${ }^{1, *}$, Tycho Anker-Nilssen $^{1}$, Kjell Einar Erikstad ${ }^{2,3}{ }^{3}$ Nils Røv ${ }^{1}$ \\ ${ }^{1}$ Norwegian Institute for Nature Research, 7485 Trondheim, Norway \\ ${ }^{2}$ Norwegian Institute for Nature Research, FRAM - High North Research Centre on Climate and the Environment, \\ 9296 Tromsø, Norway \\ ${ }^{3}$ Centre for Conservation Biology, Department of Biology, Norwegian University of Science and Technology, \\ 7049 Trondheim, Norway
}

\begin{abstract}
Current and future climate alterations might impact ecological processes like timing of breeding. We used multivariate linear models to assess the importance of food availability and climate on timing of breeding and hatching brood size of European shags Phalacrocorax aristotelis in 2 colonies, Sklinna $\left(65^{\circ} \mathrm{N}\right)$ and Røst $\left(67^{\circ} \mathrm{N}\right)$, in the Norwegian Sea over $21 \mathrm{yr}$ (1989 to 2009). Predictor variables were ICES abundance estimates of young saithe Pollachius virens, the staple food of shags in these colonies, the previous winter's North Atlantic Oscillation index (wNAO), and sea surface and air temperatures. Annual population size was included to control for density-dependent effects. The best model for hatching date explained 15\% (Sklinna) and 70\% (Røst) of the variation and showed that shags bred earlier when $1 \mathrm{yr}$ old saithe were more abundant. The model for Røst also included $2 \mathrm{yr}$ old saithe and wNAO. The best model for hatching brood size explained $40 \%$ (Sklinna) and $48 \%$ (Røst) and included a positive effect of population size at both sites. The model for Røst also included a positive effect of $1 \mathrm{yr}$ old saithe. Our study demonstrates that abundance of $1 \mathrm{yr}$ old saithe is a key factor for the breeding performance of shags in both colonies, whereas the climate variables were of less importance. Delayed breeding and low brood size were not associated with a high population of breeders, indicating breeding performance was density-independent and that the positive relationship between breeding numbers and saithe abundance mainly reflected variation in non-breeding among established breeders.
\end{abstract}

KEY WORDS: Phalacrocorax aristotelis - Norwegian Sea · Timing of breeding $\cdot$ Brood size · Pollachius virens $\cdot$ NAO

\section{INTRODUCTION}

Environmental changes caused by anthropogenic as well as natural climate alterations may have profound impacts on ecological processes and biodiversity (Walther et al. 2002, Edwards \& Richardson 2004, Thomas et al. 2004). In marine ecosystems, strong effects of climate change on the timing of seasonal activities (i.e. phenology) have been demonstrated for all trophic levels, from primary producers (e.g. Edwards \& Richardson 2004) to top predators like seabirds (e.g. Frederiksen et al. 2004, Wanless et al.

${ }^{*}$ Corresponding author: shl@nina.no
2009). For seabirds, one of the potential outcomes of climate change is seasonal mismatch between peak abundance of prey and critical periods of energy demand, such as chick rearing (e.g. Durant et al. 2007, Myksvoll et al. 2013), potentially leading to reduced breeding success and, eventually, decreasing populations (e.g. Cairns 1987).

Northern hemisphere sea surface temperature (SST) has increased by $0.71^{\circ} \mathrm{C}$ from 1850 to 2004 (Rayner et al. 2006) and is expected to increase further due to global warming (IPCC 2007). Thus, there is an urgent need to understand how temperature-

() The authors 2015. Open Access under Creative Commons by Attribution Licence. Use, distribution and reproduction are unrestricted. Authors and original publication must be credited. 
induced changes in timing and productivity at lower trophic levels can influence food availability for seabirds and other top predators. In seasonal climates, production at the lowest trophic levels typically has a pronounced spring peak and many animals respond to environmental cues that may be predictors of the peak in food availability, and adjust the timing of their breeding accordingly; cf. the match/mismatch hypothesis (Cushing 1990, see also Durant et al. 2007). For seabirds, this hypothesis has been tested in a number of studies, of which many found a mismatch between predator and prey phenologies (e.g. Visser \& Both 2005, Grémillet et al. 2006, Watanuki et al. 2009, Burthe et al. 2012, but see Durant et al. 2005). One general problem with the match/mismatch hypothesis, however, is that it ignores the level of food abundance, which can compensate for small mismatches in timing (cf. Durant et al. 2005). For marine top predators such as fish-eating seabirds, spring peaks at lower trophic levels might not be relevant cues as their main prey does not depend on phytoplankton but on secondary and higher level consumers (e.g. crustaceans such as copepods and krill), that might or might not display seasonal peaks. Thus, the numerical abundance of fish prey, which might vary considerably between years, may be the most important information for deciding if and when to breed and how many eggs to lay. Such mechanisms can operate if there is a threshold in the abundance of the prey required by the predator, and if prey is available for longer when above this threshold, enabling the predator to advance breeding. Advanced breeding is also often accompanied with an increase in the number of eggs laid (Monaghan et al. 1989, Moe et al. 2009, Shultz et al. 2009).

However, several studies have shown that seabird breeding phenology and success is associated with climate variables, such as large-scale climatic signals like the North Atlantic Oscillation (NAO, Hurrell et al. 2003) (e.g. Durant et al. 2004a, Sandvik et al. 2012, 2014), or local conditions like SST, spring air temperature, and wind conditions (e.g. Durant et al. 2004b and references therein). For instance, Frederiksen et al. (2004) demonstrated that the phenology of 2 dispersive species, the black-legged kittiwake Rissa tridactyla and the common guillemot Uria aalge were correlated with NAO, whereas the more resident species European shag Phalacrocorax aristotelis was more affected by local conditions reflected by SST around the colony. Furthermore, species and species groups may respond differently to climate change with timing of breeding being positively correlated with NAO in some species and at the same time neg- atively correlated with climatic signals in other species (Wanless et al. 2009). Such effects may also vary across regions and are most often indirect through changes in the birds' food supply (e.g. Durant et al. 2004b, Burthe et al. 2012, Sydeman et al. 2012), although it is difficult to exclude any direct effects (e.g. Aebischer 1986, Daunt et al. 2006). Few studies, however, have been able to test the combined effects of climate variables and prey abundance on seabird breeding phenology and brood size.

Here, we explore the effects of climate and prey abundance in the Norwegian Sea on timing of breeding and hatching brood size of European shags Phalacrocorax aristotelis in Norway. Cook \& Heath (2005) demonstrated a close positive correlation between recruitment, spawning-stock biomass and SST for saithe Pollachius virens in the North Sea. Although no such correlations have been published for the Northeast Arctic saithe in the Norwegian Sea, SSTs have been increasing there since 1990 (e.g. Ottersen 2010), and the size of the spawning stock of Northeast Arctic saithe (hereafter saithe) increased steeply until 2005 followed by a substantial decrease thereafter (ICES 2013, Mehl 2013). Young saithe of this stock is the most important forage fish for European shags (hereafter shag) breeding in colonies along the central Norwegian coast (e.g. Hillersøy \& Lorentsen 2012, T. Anker-Nilssen unpubl. data). Concurrent with the stock increase of Northeast Arctic saithe during the 1990s and early 2000s, the Norwegian breeding population of shag also increased (Barrett et al. 2006), and Bustnes et al. (2013) demonstrated that the annual population growth rates of shags in 2 colonies in the Norwegian Sea were positively correlated with the abundance of $1 \mathrm{yr}$ old saithe and negatively correlated with the lagged (1 yr) NAO winter index.

In this study we follow up on Bustnes et al. (2013) and explore the relationships between saithe abundance and 2 aspects of the shags' reproductive performance: the timing of their breeding and their brood size at hatching, and test how these parameters are affected by the abundance of young saithe and the size of the breeding population. When controlling for any density-dependent effects of shag population size, we expect that, in years with high abundance of saithe, hatching brood size will be higher than in years with low saithe abundance. Furthermore, as the shags from our study colonies (Sklinna and Røst) remain on the central Norwegian coast throughout the year (Bakken et al. 2003) and the adults often stay close to the colonies in winter (F. Daunt, T. AnkerNilssen, S.-H. Lorentsen unpubl. data), we expect 
that they are able to explore the abundance of 1 and 2 yr old saithe, as these are the only age-groups that are available in the vicinity of the colonies before the onset of breeding (see below). Thus, we expected that the shags breed earlier in years with high abundance of saithe. Moreover, as shags are exposed to both large-scale and local climatological factors we also wanted to explore how their reproductive performance and the availability of their staple food during the breeding season interact with these factors.

\section{MATERIALS AND METHODS}

\section{Shag data}

Annual data on shag population size and breeding performance (expressed by counts of nests and nest contents) were collected as part of the Norwegian monitoring programme for seabirds (e.g. Barrett et al. 2006, Lorentsen \& Christensen-Dalsgaard 2009) and the seabird monitoring and mapping programme SEAPOP (e.g. Anker-Nilssen et al. 2006). We used data from 2 colonies: (1) Heimøya $\left(65^{\circ} 13^{\prime} \mathrm{N}, 10^{\circ} 58^{\prime} \mathrm{E}\right)$, the largest shag colony in Sklinna, a small archipelago situated $\sim 20 \mathrm{~km}$ off the mainland coast of Nord-Trøndelag in central Norway, and (2) the island of Ellefsnyken $\left(67^{\circ} 27^{\prime} \mathrm{N}, 11^{\circ} 55^{\prime} \mathrm{E}\right)$, which holds the largest shag colony in Røst, the outermost municipality of the Lofoten Islands, situated $100 \mathrm{~km}$ west of the mainland coast in Nordland (Fig. 1) (see Bustnes et al. 2013 for details on population sizes and trends). The counts were aimed for consistent long-term monitoring of population size and unfortunately the field work at the 2 sites did not coincide in time. This prevented direct comparisons of nest contents and called for simple ways of estimating indices that reflect timing of breeding and brood size at the same time of season (peak of hatching) as detailed below.

We used data from the period 1989 to 2009, which includes all years with complete data sets from both colonies and parallel data on abundance of 1 and $2 \mathrm{yr}$ old saithe. Population size in each colony was determined by nest counts in study plots in early June (Heimøya, hereafter Sklinna) and June-July (Ellefsnyken, hereafter Røst). At both sites the study plots covered the whole colony, and nest content (whenever visible) was registered for all nests concurrently with the monitoring of population size. At Sklinna,

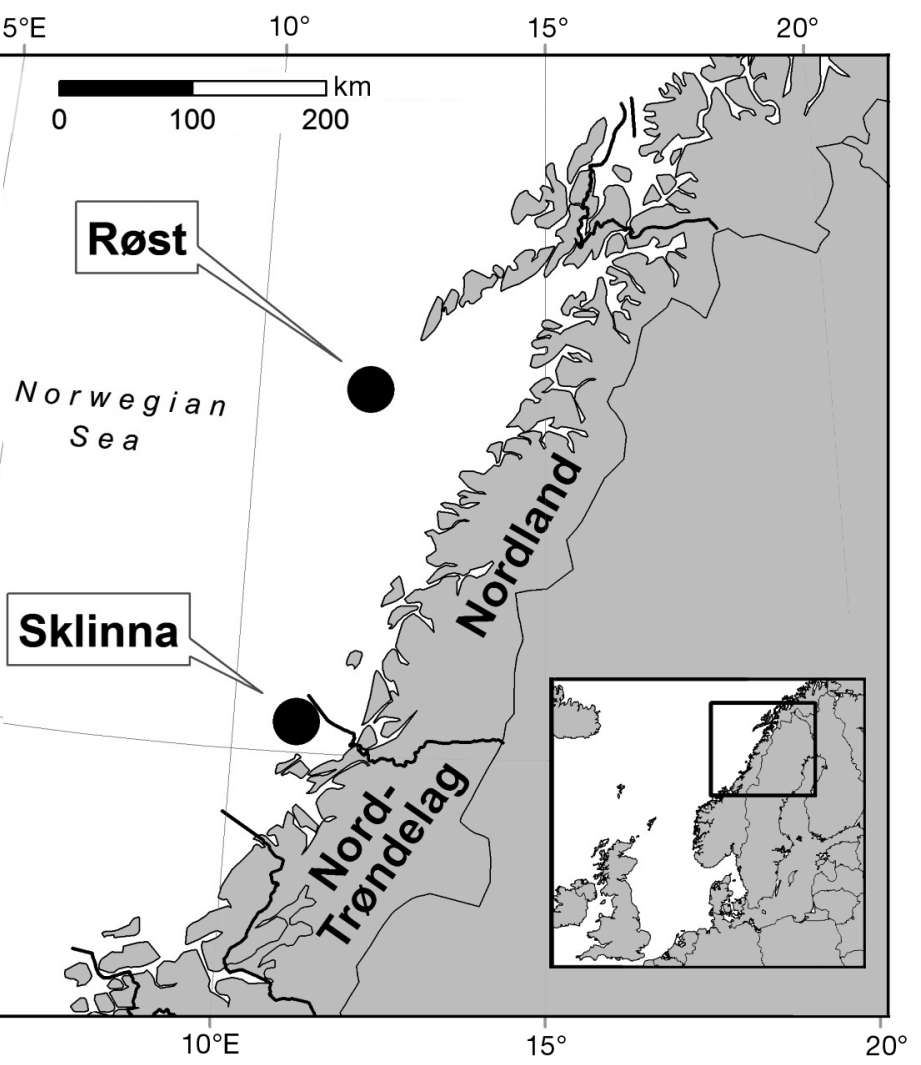

Fig. 1. Location of the study colonies, Sklinna and Røst

this usually took place during 1 to 2 consecutive days in the first 2 wk of June (range 28 May to 15 June, mean 7 to 8 June) when $0-60 \%$ (mean $14 \%$ ) of the nests contained at least 1 chick $(0 \%$ had hatched in 2008 and 2009). The work at Røst started on average $13 \mathrm{~d}$ (range 0-27) later when hatching had occurred in $0-76 \%$ (mean $35 \%$ ) of the nests ( $0 \%$ in 1996), and the counts of the 9 different plots were spread over a longer period of time (mean $23 \mathrm{~d}$, range 2-39). As annual proxies of timing of breeding and hatching brood size in our analysis, we used estimates of the median hatch date (i.e. when hatching had occurred in $50 \%$ of the nests) and of the mean number of eggs plus chicks in all nests inspected (including empty nests) at the same date (hereafter termed 'hatching brood size'). Due to the different timing of the field work, slightly different approaches were used to calculate these parameters for the 2 colonies. For Sklinna, the mean progress of hatching in the years 2007 to $2012(x=4.03 \times \ln (101.62 / y-1)-0.90$, where $x=$ deviation from median hatching day and $y=\%$ hatched), calculated by a 3 parameter sigmoidal regression from annual subsamples of about 50 nests checked at $5 \mathrm{~d}$ intervals throughout most of the breeding season (S.-H. Lorentsen unpubl. data), was 
used in all years to estimate the median hatch date for the nests in the population monitoring plots. Similarly, annual hatching brood size on these dates was estimated in the same way by using the corresponding mean rate of change in hatching brood size $\left(-0.008\right.$ eggs or chicks $\left.\mathrm{d}^{-1}\right)$ calculated for the same sub-samples of nests. At Røst, the field work covered the week of peak hatching in 14 of the 21 years, which enabled estimating the median hatch date more reliably from a linear regression between the observed proportions hatched in each study plot against the day of visit in the same year. The same approach was used to estimate annual hatching brood size in these years. For the other years, when hatching had already occurred in 70 to $76 \%$ of the nests before the first visit (6 years) or only $20 \%$ had hatched before the last visit (one extreme year, 1996), we extrapolated from these proportions by applying the mean regression rate of hatching $\left(2.36 \% \mathrm{~d}^{-1}\right)$ in 17 other years (1989 to 2012) when field work covered the peak of hatching more adequately. Hatching brood size was then estimated using the mean rate of change in clutch size between median hatch date and the date of first visit (6 years, -0.012 to -0.011 eggs or chicks $\mathrm{d}^{-1}$ ) or last visit ( 1 year, -0.006 eggs or chicks $\mathrm{d}^{-1}$ ).

\section{Climate variables}

The winter NAO index (December to February) was used as a proxy for large-scale climate variation. Using NAO as a proxy is favourable since it has been demonstrated that large-scale climate indices often better predict variation in ecological processes than local climate parameters (Hurrell et al. 2003). Data on the station-based winter NAO index (wNAO) for all relevant years were obtained from www.cgd.ucar. edu/staff/jhurrell/ and entered unlagged as a covariate in the analyses (Fig. 2).

Sea surface temperature (SST), averaged for February to April, was used as a proxy for the environmental conditions experienced by young saithe and other potential prey in the colony area during the prebreeding period of the shags. The SST data, averaged over a $2^{\circ} \times 2^{\circ}$ grid around each colony were obtained from http://iridl.ldeo.columbia.edu/SOURCES/. NOAA/.NCDC/.ERSST/.version3b/ (Smith et al. 2008) and entered as colony-specific covariates in the analyses (Fig. 2).

Winter air temperatures (wAT) from the meteorological stations at Sklinna and Røst were averaged for December to February and used as an additional proxy to NAO of the local environmental conditions experienced by wintering shags. The data were obtained from www.yr.no and entered as mean values for the 2 colonies in the analyses (Fig. 2).

\section{Fish data}

The Northeast Arctic saithe stock spawns in pelagic waters in the eastern part of the Norwegian Sea in late winter (peaks in February), and the young fish move into the kelp forest in shallow coastal waters along the Norwegian coast during their first summer where they stay until they recruit to the pelagic stock when $3 \mathrm{yr}$ old (Mehl et al. 2011).

All data on the variation in abundance of young saithe were extracted from the latest report of the ICES Arctic Fisheries Working Group (ICES 2013) with permission from ICES. These data were

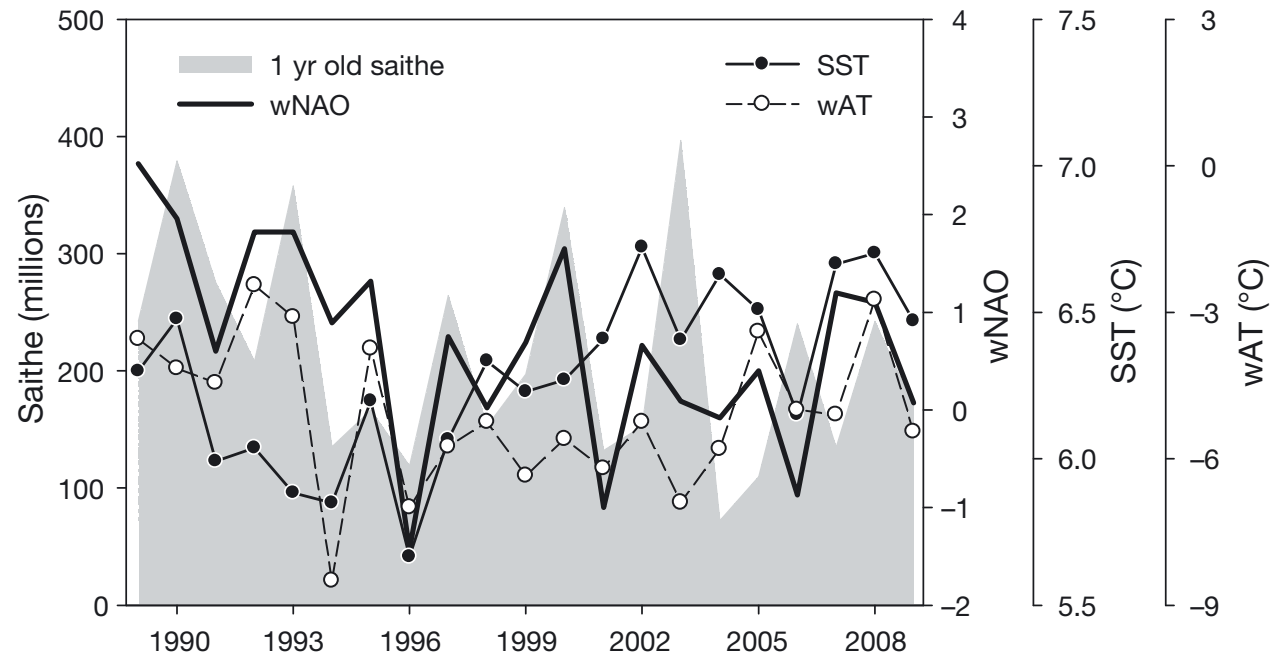

Fig. 2. Annual variation in abundance (individuals) of $3 \mathrm{yr}$ old saithe Pollachius virens (backlagged by 2 yr to indicate $1 \mathrm{yr}$ old saithe), winter (December to March) North Atlantic Oscillation index (wNAO), mean sea surface temperature (SST) from February to April within a $2^{\circ} \times$ $2^{\circ}$ block around the colony, and mean winter (December to February) air temperature (wAT) at the colony. For simplicity, SST and wAT are presented as the average of the values for Sklinna and Røst, which were strongly correlated (SST: $\mathrm{r}^{2}=0.98, \mathrm{p}<$ 0.001; wAT: $\mathrm{r}^{2}=0.59, \mathrm{p}<0.001$ ) 
derived from the extended survivor's analysis (XSA) assessment of the Northeast Arctic saithe stock, which spawns along the Norwegian coast between 62 and $69^{\circ} \mathrm{N}$ (ICES 2013). The model is based on age-specific data on catch numbers, weight and maturity and a fixed natural mortality and is tuned by CPUE data from trawl fisheries and indices from an acoustic survey. We used the abundance estimates for saithe recruits at age 3 as indices of $1 \mathrm{yr}$ old (Saithe[1]) and $2 \mathrm{yr}$ old saithe (Saithe[2]) by backdating them by 2 and 1 years, respectively. As in our previous study (Bustnes et al. 2013), we had no data to account for possible inter-annual variation in mortality rates of the youngest age classes when lagging the data. All fish data were log-transformed prior to analysis to achieve linear relationships on a log scale.

\section{Statistical analyses}

All analyses were carried out in SAS v. 9.2 (SAS 2008). Before their use in further analyses, parameters with significant temporal trends were detrended by using the residuals from their linear relationship with year. Multivariate linear regression models (PROC REG) were then used to examine the associations between hatching brood size, hatching date and population size, and the various covariates. We used the command 'white' in PROC REG to obtain heteroscedastic-consistent standard errors when necessary, and applied autoregressive models (PROC AUTOREG) to test for any covariance in error structure over time. Models with different covariates were compared using Akaike's Information Criterion corrected for small sample sizes $\left(\mathrm{AIC}_{\mathrm{c}}\right)$, preferring models with the lowest $\triangle \mathrm{AIC}_{\mathrm{C}}$ (and highest model likelihood; Burnham \& Anderson 2002). Non-nested models within $2 \Delta \mathrm{AIC}_{\mathrm{c}}$ units of each other were considered to be equally well supported, whereas models nested within the top rank model were considered unsupported if they contained more parameters, even if their $\Delta \mathrm{AIC}_{\mathrm{c}}$ was $<2$.

As a final step, we ran autoregressive models (PROC AUTOREG) and used the $\mathrm{ARCH}$ test to explore if there were any 1 to 3 yr lagged autocorrelation in the error structure for the best models.

\section{RESULTS}

\section{Long-term trends and bivariate correlations}

Breeding population size of shags increased during the study period in both colonies (Table 1), and was highly correlated $(\mathrm{r}=0.64, \mathrm{p}<0.01)$. Hatching date also increased in both colonies (Fig. 3, Table 1), but did not correlate between the colonies $(r=0.29, p>$ 0.05 ) or with population size (Sklinna $r=-0.25, p>$ 0.05 ; Røst $r=0.16, p>0.05$ ). We did not detect any correlation in hatching brood size between the 2 colonies $(r=0.38, p>0.05)$, although hatching brood size was correlated to population size at both colonies (Sklinna $\mathrm{r}=0.63, \mathrm{p}<0.01$; Røst $\mathrm{r}=0.53, \mathrm{p}<$ 0.05). In both cases, hatching brood size also correlated strongly with median hatch date (Sklinna $\mathrm{r}=$ $-0.49, \mathrm{p}<0.05$; Røst $\mathrm{r}=-0.62, \mathrm{p}<0.01$ ).

SST increased significantly during the study period, whereas wNAO showed a similar decrease and wAT was stable (Table 1). As is typical for climate parameters, there was some autocorrelation between these variables in the study period (Table 2 ), but we considered it sufficiently moderate $\left(\right.$ all $\left.\mathrm{r}^{2}<0.3\right)$ to justify that we entered them all into the same model. As only one of them (wNAO) ended up in a top rank model (see 'Results'), there is no reason to expect this biased the interpretation of our results.

There were no temporal trends in the populations of 1 and 2 yr old saithe during the study period (Table 1). Population size of $1 \mathrm{yr}$ old saithe correlated positively with wNAO $(\mathrm{r}=0.49, \mathrm{p}<0.05)$, but not with SST $(\mathrm{r}=$ $0.11, p>0.05)$ or wAT $(r=0.24, p>0.05)$. No such correlations were observed for $2 \mathrm{yr}$ old saithe.

Table 1. Tests for yearly linear trends in parameters used to examine the relationship between median hatch date and the contemporary hatching brood size of shags Phalacrocorax aristotelis at 2 colonies (Sklinna and Røst, Norway) and various environmental factors. Sample size $=21$ (number of years from 1989 to 2009) for all parameters. Parameters with temporal trends were normalised before analyses by using the residuals from a regression with year

\begin{tabular}{|lccc|}
\hline Parameter & Slope $( \pm \mathrm{SE})$ & $\mathrm{r}^{2}$ & $\mathrm{p}$ \\
\hline Population size Sklinna & $0.071(0.0009)$ & 0.75 & $<0.0001$ \\
Population size Røst & $0.049(0.012)$ & 0.46 & 0.0008 \\
Median hatch date Sklinna & $0.673(0.236)$ & 0.56 & $<0.0001$ \\
Median hatch date Røst & $1.711(0.283)$ & 0.66 & $<0.0001$ \\
Hatching brood size Sklinna & $-0.035(0.010)$ & 0.39 & 0.002 \\
Hatching brood size Røst & $-0.020(0.020)$ & 0.06 & 0.29 \\
1 yr old saithe & $-0.037(0.016)$ & 0.22 & 0.03 \\
2 yr old saithe & $-0.014(0.019)$ & 0.03 & 0.47 \\
SST (February to April) & $0.027(0.009)$ & 0.35 & 0.005 \\
wNAO (December to March) & $-0.078(0.033)$ & 0.22 & 0.03 \\
wAT (December to February) & $-0.034(0.056)$ & 0.02 & 0.55 \\
\hline
\end{tabular}



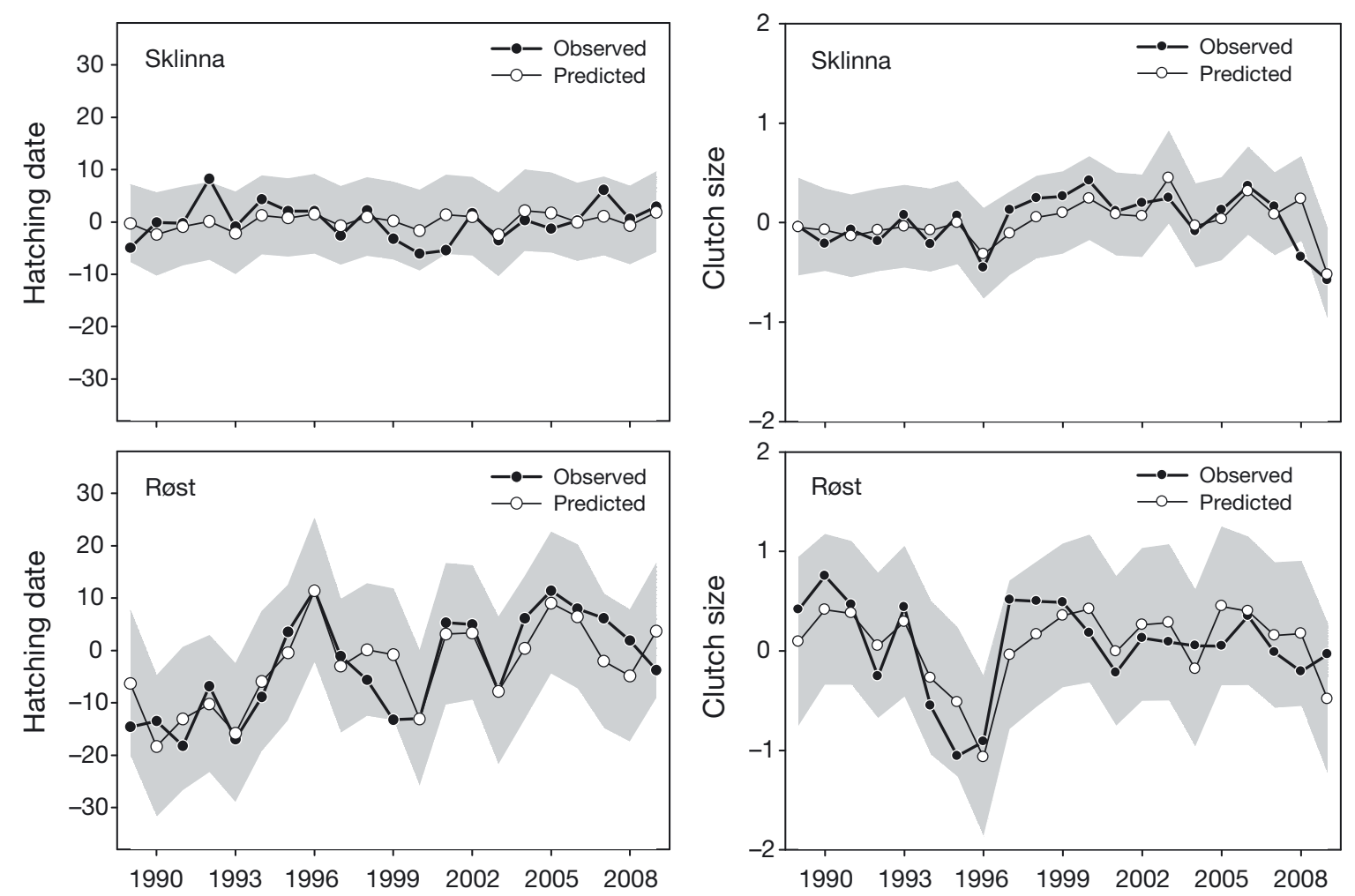

Fig. 3. Annual variation in median hatch date and the contemporary hatching brood size of shags Phalacrocorax aristotelis at 2 colonies (Sklinna and Røst, Norway) from 1989 to 2009. Data is presented as deviance from the overall mean (0 on the $y$-axis), and predicted values with $95 \%$ CI (grey shading) from the top-ranked model (see Tables 3-5)

Table 2. Correlation matrix for different parameters used to estimate the yearly variation in median hatch date and the contemporary hatching brood size in 2 shag Phalacrocorax aristotelis colonies (Sklinna and Røst, Norway). Sample size is 21 (number of years from 1989 to 2009) for all correlations. Parameters: winter NAO (wNAO), winter air temperature (wAT), sea surface temperature (SST), 1 yr old saithe (Saithe[1]) and 2 yr old saithe (Saithe[2]). *Significant (p < 0.05) correlations (in bold)

\begin{tabular}{|llrrr|}
\hline & Saithe[2] & SST & wAT & wNAO \\
\hline Saithe[1] & -0.19 & 0.11 & 0.24 & $\mathbf{0 . 4 9}^{*}$ \\
Saithe[2] & & -0.03 & -0.29 & -0.14 \\
SST & & & 0.38 & $\mathbf{0 . 4 9}^{*}$ \\
wAT & & & & $\mathbf{0 . 5 4}^{*}$ \\
\hline
\end{tabular}

\section{Multivariate models for timing of hatching}

In both colonies, the best model for median hatch date included a negative effect of 1 yr old saithe (Table 3), i.e. hatching occurred earlier in years with high abundance of saithe. The model for Røst accounted for $70 \%$ of the variation in hatch date and also included equi-directional effects of $2 \mathrm{yr}$ old saithe and wNAO, which explained $14 \%$ and $12 \%$ respectively, while the model for Sklinna explained only $15 \%$ and contained no additional covariates (Table 4). The second best model for Sklinna included also wNAO and had an $\mathrm{AIC}_{\mathrm{c}}$ value 0.88 units higher than the top-ranked model (Table 3), whereas the second best model for Røst included 4 covariates ( 1 and 2 yr old saithe, wNAO and wAT), and had a 1.3 units higher $\mathrm{AIC}_{\mathrm{C}}$ than the top ranked model. These models are also less plausible as they contain one parameter more and were nested within the top ranked models.

The total AIC weight for all models of hatching dates including $1 \mathrm{yr}$ old saithe was 0.65 and 0.95 for Sklinna and Røst, respectively. At both colonies, wNAO and wAT contributed to models within $2 \mathrm{AIC}_{\mathrm{c}}$ units of the top-ranked model, as did SST at Røst.

\section{Multivariate models for brood size}

For both colonies, the best model for hatching brood size included a positive effect of population size (Table 5), i.e. the brood size was larger in years with large population sizes. The model for Sklinna explained $40 \%$ of the variation and included no other 
Table 3. Comparison of candidate models describing the annual variation in median hatch date of shags Phalacrocorax aristotelis breeding at 2 colonies (Sklinna and Røst, Norway) from 1989 to 2009. Parameters: winter NAO (wNAO), winter air temperature (wAT), sea surface temperature (SST), population size (Pop.size), 1 yr old saithe (Saithe[1]) and 2 yr old saithe (Saithe[2]). Models are ranked by $\Delta \mathrm{AIC}_{\mathrm{C}}$, but model likelihood (ML), AIC weight (AICwt) and $\mathrm{r}^{2}$ are also given. Only models with $\Delta \mathrm{AIC}_{\mathrm{C}}<5$ are shown

\begin{tabular}{|c|c|c|c|c|c|c|}
\hline Rank & Colony/model & $\mathrm{AIC}_{\mathrm{c}}$ & $\Delta \mathrm{AIC}_{\mathrm{c}}$ & ML & AICwt & $\mathrm{r}^{2}$ \\
\hline & Sklinna & & & & & \\
\hline 1 & Saithe[1] & 54.44 & 0.00 & 1.00 & 0.11 & 0.15 \\
\hline 2 & Saithe[1] + wNAO & 55.32 & 0.88 & 0.64 & 0.07 & 0.21 \\
\hline 3 & Saithe[1] + Saithe[2] & 55.74 & 1.30 & 0.52 & 0.06 & 0.20 \\
\hline 4 & Pop.size & 55.98 & 1.54 & 0.46 & 0.05 & 0.09 \\
\hline 5 & Saithe[1] + wAT & 56.12 & 1.68 & 0.43 & 0.05 & 0.18 \\
\hline 6 & Saithe[2] & 56.25 & 1.82 & 0.40 & 0.04 & 0.08 \\
\hline 7 & Saithe[1] + Pop.size & 56.61 & 2.17 & 0.34 & 0.04 & 0.16 \\
\hline 8 & Saithe[1] + Saithe[2] + wNAO & 56.72 & 2.29 & 0.32 & 0.03 & 0.26 \\
\hline 9 & Saithe[1] + Saithe[2] + wAT & 56.77 & 2.33 & 0.31 & 0.03 & 0.26 \\
\hline 10 & Saithe[1] + SST & 56.83 & 2.39 & 0.30 & 0.03 & 0.15 \\
\hline 11 & Saithe[1] + wNAO + SST & 56.87 & 2.43 & 0.30 & 0.03 & 0.26 \\
\hline 12 & Saithe[2] + Pop.size & 57.66 & 3.22 & 0.20 & 0.02 & 0.12 \\
\hline 13 & SST & 57.68 & 3.24 & 0.20 & 0.02 & 0.01 \\
\hline 14 & wAT & 57.78 & 3.34 & 0.19 & 0.02 & 0.01 \\
\hline 15 & Pop.size + wAT & 57.81 & 3.37 & 0.19 & 0.02 & 0.11 \\
\hline 16 & Saithe[1] + Pop.size + wNAO & 57.89 & 3.45 & 0.18 & 0.02 & 0.22 \\
\hline 17 & wNAO & 57.89 & 3.45 & 0.18 & 0.02 & 0.00 \\
\hline 18 & Saithe[2] + wAT & 57.99 & 3.55 & 0.17 & 0.02 & 0.11 \\
\hline 19 & Saithe[1] + wNAO + wAT & 58.00 & 3.57 & 0.17 & 0.02 & 0.22 \\
\hline 20 & Saithe[1] + SST + wAT & 58.13 & 3.70 & 0.16 & 0.02 & 0.21 \\
\hline 21 & $\begin{array}{l}\text { Saithe[1] + Saithe[2] + SST } \\
\text { + wAT }\end{array}$ & 58.24 & 3.80 & 0.15 & 0.02 & 0.32 \\
\hline 22 & Pop.size + wNAO & 58.29 & 3.85 & 0.15 & 0.02 & 0.09 \\
\hline 23 & Saithe[1] + Pop.size + wAT & 58.35 & 3.91 & 0.14 & 0.01 & 0.20 \\
\hline 24 & Pop.size + SST & 58.36 & 3.92 & 0.14 & 0.01 & 0.09 \\
\hline 25 & Saithe[1] + Saithe[2] + SST & 58.41 & 3.97 & 0.14 & 0.01 & 0.20 \\
\hline 26 & $\begin{array}{l}\text { Saithe[1] + Saithe }[2]+\text { wNAO } \\
+ \text { SST }\end{array}$ & 58.41 & 3.97 & 0.14 & 0.01 & 0.31 \\
\hline 27 & Saithe[1] + Saithe[2] + Pop.size & 58.44 & 4.00 & 0.14 & 0.01 & 0.20 \\
\hline 28 & Saithe[2] + SST & 58.47 & 4.04 & 0.13 & 0.01 & 0.09 \\
\hline 29 & Saithe[2] + wNAO & 58.64 & 4.20 & 0.12 & 0.01 & 0.08 \\
\hline 30 & Saithe[2] + Pop.size + wAT & 59.24 & 4.80 & 0.09 & 0.01 & 0.17 \\
\hline 31 & Saithe[2] + SST + wAT & 59.25 & 4.82 & 0.09 & 0.01 & 0.17 \\
\hline 32 & Saithe[1] + Pop.size + SST & 59.31 & 4.88 & 0.09 & 0.01 & 0.17 \\
\hline \multirow[t]{2}{*}{33} & $\begin{array}{l}\text { Saithe[1] + Saithe[2] + wNAO } \\
\text { + wAT }\end{array}$ & 59.32 & 4.89 & 0.09 & 0.01 & 0.28 \\
\hline & Røst & & & & & \\
\hline 1 & Saithe[1] + Saithe[2] + wNAO & 78.70 & 0.00 & 1.00 & 0.31 & 0.70 \\
\hline 2 & $\begin{array}{l}\text { Saithe[1] + Saithe[2] + wNAO } \\
\text { + wAT }\end{array}$ & 80.00 & 1.30 & 0.52 & 0.16 & 0.72 \\
\hline 3 & $\begin{array}{l}\text { Saithe[1] + Saithe[2] + wNAO } \\
+ \text { SST }\end{array}$ & 80.57 & 1.87 & 0.39 & 0.12 & 0.72 \\
\hline 4 & $\begin{array}{l}\text { Saithe[1] + Saithe[2] + Pop.size } \\
\text { + wNAO }\end{array}$ & 81.07 & 2.37 & 0.31 & 0.10 & 0.71 \\
\hline 5 & $\begin{array}{l}\text { Saithe[1] + Saithe[2] + wNAO } \\
\text { + SST + wAT }\end{array}$ & 82.03 & 3.32 & 0.19 & 0.06 & 0.75 \\
\hline 6 & Saithe[1] + Saithe[2] & 83.08 & 4.38 & 0.11 & 0.04 & 0.57 \\
\hline 7 & $\begin{array}{l}\text { Saithe[1] + Saithe[2] + Pop.size } \\
\text { + wNAO + wAT }\end{array}$ & 83.11 & 4.41 & 0.11 & 0.03 & 0.73 \\
\hline
\end{tabular}

covariates, whereas that for Røst explained $48 \%$ and also included an equally important positive effect of 1 yr old saithe abundance (Table 6). The second best model for Sklinna explained no more of the variation than the best model, but included abundance of $2 \mathrm{yr}$ old saithe in addition to population size, while the second best model for Røst included the abundance of both 1 and 2 yr old saithe as well as wAT (Table 3). However, not only did these models have higher $\mathrm{AIC}_{\mathrm{C}}$ values (2.34 and 1.24 units for Sklinna and Røst, respectively), but they were also considered less plausible because they had 1 parameter more and were nested within the top-ranked models.

The total AIC weight values for all models including $1 \mathrm{yr}$ old saithe was 0.17 and 0.84 for Sklinna and Røst, respectively. None of the climate variables contributed to models within $2 \mathrm{AIC}_{\mathrm{c}}$ units of the topranked model at Sklinna, and only wAT contributed at Røst.

For median hatch date there was no autocorrelation in the error structure for the best models (all $p$ > 0.36), but hatching brood size at both colonies could be best fitted to an AR1 model (Sklinna $t=-1.99$, $\mathrm{p}=0.06$; Røst $t=-2.17, \mathrm{p}=0.04)$. Correcting for this autocorrelation increased the predictive power of the models from $40 \%$ to $53 \%$ for Sklinna and from $48 \%$ to $57 \%$ for Røst.

\section{DISCUSSION}

Due to huge inter-annual variation in the onset of breeding, the field work did not cover the peak of hatching in all years. For $18 \mathrm{yr}$ at Sklinna and 7 yr at Røst, we therefore estimated the date of $50 \%$ hatched by applying the average rate of hatching in years when field work was better timed. For the 
Table 4. Estimated slopes, explained variance (partial and for the model) and variance inflation factor (VIF) for the variables best explaining the annual variation in mean hatching dates of shags Phalacrocorax aristotelis at 2 colonies (Sklinna and Røst, Norway) from 1989 to 2009. Estimates are from the top rank model in Table 3. Parameters: winter NAO (wNAO), 1 yr old saithe (Saithe[1]) and $2 \mathrm{yr}$ old saithe (Saithe[2]). Standard errors (SE) and p-values are adjusted for heteroscedasticity (not constant variance over time)

\begin{tabular}{|lcccccc|}
\hline $\begin{array}{l}\text { Colony/ } \\
\text { variable }\end{array}$ & Estimate (SE) & $t$ & Pr $>|t|$ & $\begin{array}{c}\text { Partial } \\
\mathrm{r}^{2}\end{array}$ & $\begin{array}{c}\text { Model } \\
\mathrm{r}^{2}\end{array}$ & VIF \\
\hline Sklinna & & & & & & \\
Intercept & $0.3744(0.7709)$ & 0.49 & 0.6327 & & & \\
Saithe[1] & $-0.00002(0.000008)$ & -1.85 & 0.0804 & 0.15 & 0.15 & \\
Røst & & & & & & \\
Intercept & $1.2573(1.0452)$ & 1.2 & 0.2455 & & & \\
Saithe[1] & $-0.00005(0.00001)$ & -4.85 & 0.0001 & 0.44 & 0.44 & 1.34 \\
Saithe[2] & $-0.00004(0.00001)$ & -3.54 & 0.0025 & 0.14 & 0.58 & 1.04 \\
wNAO & $-3.8221(1.0651)$ & -3.59 & 0.0023 & 0.12 & 0.70 & 1.32 \\
\hline
\end{tabular}

recent study based on fish otoliths in pellets regurgitated by adults (Hillersøy \& Lorentsen 2012, S.-H. Lorentsen unpubl. data), it was found that saithe comprised between $27 \%$ and $89 \%$ (mean $68 \%$ ) of the diet biomass of shags at Sklinna during the breeding seasons 2007 to 2012. Saithe is also the most common prey of shags breeding at Røst (Anker-Nilssen 2005, T. Anker-Nilssen unpubl. data). Although Bustnes et al. (2013) demonstrated that population size in the previous year negatively affected the annual rate of population change in our study colonies, in this study we show that a high population size did not delay breeding or reduce brood

other $14 \mathrm{yr}$ at Røst, the estimation could be made more reliably because the longer period of field work covered the peak of hatching and allowed use of the hatching rate from the same year. Consequently, we expect the estimates for Sklinna to be more biased than those for Røst, which may well explain why the best model for this colony only explained $21 \%$ of the variation in timing, whereas that for Røst accounted for as much as $70 \%$. A similar difference was not evident for hatching brood size.

Our study indicates that shags in the Norwegian Sea only depend to a minor degree on climatic cues for timing of their breeding (e.g. Burthe et al. 2012, but see Frederiksen et al. 2004, Wanless et al. 2009), but phenological relationships may be masked by high abundance and/or broad peaks of seasonal prey (Durant et al. 2005). More importantly, we demonstrate that the shags' timing of breeding as well as their hatching brood size is closely correlated with stock abundance estimates of the available age groups of saithe also found in their diet. These results strongly support previous assumptions that saithe is a key prey species for shags breeding in the Norwegian Sea (e.g. Anker-Nilssen 2005, Hillersøy \& Lorentsen 2012, Bustnes et al. 2013). In a
Table 5. Comparison of candidate models describing the annual variation in hatching brood size of shags Phalacrocorax aristotelis breeding at 2 colonies (Sklinna and Røst, Norway) from 1989 to 2009. Parameters: winter NAO (wNAO), winter air temperature (wAT), sea surface temperature (SST), population size (Pop.size), 1 yr old saithe (Saithe[1]) and $2 \mathrm{yr}$ old saithe (Saithe[2]). Models are ranked by $\Delta \mathrm{AIC}_{\mathrm{C}}$, but model likelihood (ML), AIC weight (AICwt) and $\mathrm{r}^{2}$ are also given. Only models with $\Delta \mathrm{AIC}_{\mathrm{c}}$ $<5$ are shown

\begin{tabular}{|c|c|c|c|c|c|c|}
\hline Rank & Colony/model & $\mathrm{AIC}_{\mathrm{c}}$ & $\Delta \mathrm{AIC}_{\mathrm{c}}$ & ML & AICwt & $r^{2}$ \\
\hline & Sklinna & & & & & \\
\hline 1 & Pop.size & -62.92 & 0.00 & 1.00 & 0.29 & 0.40 \\
\hline 2 & Saithe[2] + Pop.size & -60.58 & 2.34 & 0.31 & 0.09 & 0.40 \\
\hline 3 & Pop.size + wAT & -60.53 & 2.38 & 0.30 & 0.09 & 0.40 \\
\hline 4 & Pop.size + wNAO & -60.42 & 2.50 & 0.29 & 0.08 & 0.40 \\
\hline 5 & Saithe[1] + Pop.size & -60.41 & 2.51 & 0.29 & 0.08 & 0.40 \\
\hline 6 & Pop.size + SST & -60.40 & 2.51 & 0.28 & 0.08 & 0.40 \\
\hline 7 & $\begin{array}{l}\text { Saithe[2] + Pop.size + wAT } \\
\text { Røst }\end{array}$ & -57.98 & 4.93 & 0.08 & 0.02 & 0.41 \\
\hline 1 & Saithe[1] + Pop.size & -39.64 & 0.00 & 1.00 & 0.24 & 0.48 \\
\hline 2 & Saithe[1] + Pop.size + wAT & -38.40 & 1.24 & 0.54 & 0.13 & 0.52 \\
\hline 3 & Saithe[1] + Saithe[2] + Pop.size & -37.88 & 1.76 & 0.42 & 0.10 & 0.51 \\
\hline 4 & Saithe[1] + Pop.size + SST & -37.42 & 2.22 & 0.33 & 0.08 & 0.49 \\
\hline 5 & Saithe[1] + Pop.size + wNAO & -36.84 & 2.81 & 0.25 & 0.06 & 0.48 \\
\hline 6 & Saithe[1] + Pop.size + SST + wAT & -36.08 & 3.57 & 0.17 & 0.04 & 0.54 \\
\hline 7 & Saithe[1] + Saithe[2] + Pop.size + wAT & -35.98 & 3.66 & 0.16 & 0.04 & 0.54 \\
\hline 8 & Saithe[1] + Pop.size + wNAO + wAT & -35.77 & 3.87 & 0.14 & 0.03 & 0.53 \\
\hline 9 & Pop.size & -35.27 & 4.37 & 0.11 & 0.03 & 0.28 \\
\hline 10 & Saithe[1] + Saithe[2] + Pop.size + SST & -35.14 & 4.50 & 0.11 & 0.03 & 0.52 \\
\hline
\end{tabular}


Table 6. Estimated slopes, explained variance (partial and for the model) and variance inflation factor (VIF) for the variables best explaining the annual variation in hatching brood size of shags Phalacrocorax aristotelis at 2 colonies (Sklinna and Røst, Norway) from 1989 to 2009. Estimates are from the topranked model in Table 5. Parameters: population size (Pop.size) and 1 yr old saithe (Saithe[1]). Standard errors (SE) and p-values are adjusted for heteroscedasticity (not constant variance over time)

\begin{tabular}{|c|c|c|c|c|c|c|}
\hline $\begin{array}{l}\text { Colony/ } \\
\text { variable }\end{array}$ & Estimate (SE) & $t$ & $\operatorname{Pr}>|t|$ & $\begin{array}{c}\text { Partial } \\
\mathrm{r}^{2}\end{array}$ & $\begin{array}{c}\text { Model } \\
\mathrm{r}^{2}\end{array}$ & VIF \\
\hline \multicolumn{7}{|l|}{ Sklinna } \\
\hline Intercept & $-0.0268(0.0428)$ & -0.63 & 0.5387 & & & \\
\hline Pop.size & $0.0004(0.0001)$ & 3.44 & 0.0027 & 0.40 & 0.40 & \\
\hline \multicolumn{7}{|l|}{ Røst } \\
\hline Intercept & $-0.0216(0.0765)$ & -0.28 & 0.7812 & & & \\
\hline Saithe[1] & $0.000002(0.0000007)$ & 3.24 & 0.0046 & 0.24 & 0.24 & 1.01 \\
\hline Pop.size & $0.0015(0.0004)$ & 3.68 & 0.0017 & 0.24 & 0.48 & 1.01 \\
\hline
\end{tabular}

dropped to only 60 to $71 \%$ of that in the adjacent years and the biomass of $1 \mathrm{yr}$ old saithe in the shag diet $(24 \%)$ was nearly one third of the average $(61 \%)$ for the other years in the period 2007 to 2012 (S.-H. Lorentsen unpubl. data).

In our study, median hatch dates and wNAO did not correlate at Sklinna, but for Røst the correlation was significant and negative indicating earlier breeding after winters with high NAO indices. Moreover, the abundance of 1 yr old saithe was positively correlated with wNAO and in both colonies the shags bred earlier when more $1 \mathrm{yr}$ old saithe were available. Saithe in the North Sea has responded positively to increasing SSTs (Cook \& Heath 2005), and an earlier spawning has also been observed for saithe in Faroese waters (Homrum et al. 2012). There were no correlations between SSTs and the abundance indices of young saithe in our analysis (Table 2), nor when we back-lagged the saithe data an extra year to account for possible effects on first-year fish $(\mathrm{r}=0.08, \mathrm{p}=0.736)$. We did however use SSTs sampled around the colonies, whereas the Northeast Arctic saithe spawns further offshore along the shelf edge where the warmer Atlantic Current has more influence.

In both colonies the timing of breeding was strongly related to the abundance of $1 \mathrm{yr}$ old saithe, but the ecological links with climate and lower trophic levels are still unclear, especially since climate expressed as SST or wAT did not contribute significantly to the best models, and wNAO only explained $12 \%$ of the variation at one colony (Røst). Although the Norwegian Sea, where both colonies are situated, comprises a seasonal environment, both shags (cf. Bakken et al. 2003) and young saithe are resident in the same ecosystem throughout the year.
Thus, the shags should always be able to track the abundance of young saithe of different age classes. Daunt et al. $(2006,2014)$ showed that shorter individual foraging times in late winter, an indication of good food availability, were associated with earlier and more successful breeding. Thus pre-breeding intrinsic foraging ability was critical in determining breeding phenology, and our study suggests that this is also the case for shags breeding at Sklinna and Røst.

At both study sites the shags' hatching brood size increased with their population size, probably reflecting that more adults achieve the condition to breed and lay a bigger clutch when breeding conditions are favourable (e.g. Chastel et al. 1995, Svagelj \& Quintana 2011, Svagelj et al. 2012). There were no correlations between hatching brood size at Sklinna and climate parameters, but at both colonies hatching broods were smaller when breeding was late. This corresponds with the findings of Frederiksen et al. (2004) who demonstrated lower breeding success of shags in late years. There are at least 2 possible explanations for this pattern: (1) Late breeding and small hatching broods might, through their association with low wNAO reflecting colder weather conditions, indicate lower body conditions or increased mortality of adults before the onset of breeding. It has, at least, been shown that young shags may suffer increased mortality during harsh weather conditions (Frederiksen et al. 2008). Whether cold weather conditions during winters with negative wNAO make foraging more difficult (cf. Finney et al. 1999) and, thereby, reduce pre-breeding body conditions and delay the onset of breeding, is still unknown. However, shags, like all cormorants, need to dry off on land after each feeding bout (e.g. Grémillet et al. 2005) and may therefore be more susceptible to cold weather conditions in winter. (2) Poor feeding conditions in years of late breeding, as indicated by the negative relationships between abundance of $1 \mathrm{yr}$ old saithe and median hatch date, may reflect that the shags delayed their breeding when abundance of 1 yr old saithe was low. As 0-group (firstyear) saithe are probably not available in the shags' feeding areas early in the breeding season and do not appear as an important component of the shag diet until early July (S.-H. Lorentsen unpubl. data), it might be expected that the shags in such years could instead switch to $2 \mathrm{yr}$ old saithe, if available. How- 
ever, at Sklinna this age-group normally constitutes less than $10 \%$ of the total biomass of saithe in the shag diet (Hillersøy \& Lorentsen 2012, S.-H. Lorentsen unpubl. data), perhaps because 2 yr old saithe is $>240 \mathrm{~mm}$ long and possibly too large or fast-swimming to be an easy prey (cf. Hillersøy \& Lorentsen 2012). The relative importance of these hypotheses is still unknown.

In a longer perspective than that covered by our study, SST and wNAO are positively correlated in the Northeast Atlantic (Visbeck et al. 2001). Although there was a significant increase in SST at both Sklinna and Røst over the study period, wNAO showed an opposite trend, and wAT was variable with no overall trend. Concurrently, hatching was progressively delayed at both colonies, in contrast to many other studies documenting that earlier breeding is a common response of seabirds to a warming climate (e.g. Moe et al. 2009, Reed et al. 2009, Votier et al. 2009, Wanless et al. 2009, Watanuki et al. 2009). Delayed breeding parallel to increasing temperatures has, however, also been demonstrated for some seabird populations in both the northern (Frederiksen et al. 2004, Wanless et al. 2008, Moe et al. 2009, Shultz et al. 2009, Wanless et al. 2009) and southern hemisphere (e.g. Barbraud \& Weimerskirch 2006, Surman et al. 2012) and has sometimes been explained by a parallel decrease in food availability. Given the decadal-scale regime shifts typical for ocean climate at high latitudes (e.g. Stenseth et al. 2004), such contrasting effects are not unexpected: both prey and predator populations will respond negatively when ambient temperatures move outside (i.e. either warmer or colder) of the optimal range for the individuals' reproduction and/or survival (Irons et al. 2008). Direct physiological effects of temperature changes may also affect the predator and prey differently, especially when one spends most of the time in open air and the other lives in the sea.

The main functional responses between food abundance and different components of seabird breeding parameters need to be fully understood before implementing seabirds as indicators (Cairns 1987, Piatt et al. 2007). However, the close relationships between the breeding performance and diet of shags and the abundance of young saithe can very likely be developed into cost-efficient, early warning indicators of major shifts in saithe stock recruitment and other important changes in the coastal ecosystem of the Norwegian Sea (e.g. Barrett 1991, Anker-Nilssen 2005, Hillersøy \& Lorentsen 2012). In this context, our study adds important options for refinements by including more parameters to the equation besides the annual change in breeding numbers (Bustnes et al. 2013), although we suggest that the shags' diet should be explored in more detail. The apparent lack of density-dependent effects on median hatch date and hatching brood size acts to increase the potential value of these variables as indicators, but we emphasize the importance of collecting data during the peak of hatching to secure the most adequate estimates. The first step, standardising and continuing the monitoring effort at Sklinna and Røst, has been undertaken. The next step should be to explore if the seasonal abundance and age structure of saithe in the diet of these shags underpin the relationships already demonstrated.

Acknowledgements. This study was carried out as part of the SEAPOP programme (www.seapop.no), which is financed by the Norwegian Ministry of Environment via its Environmental Agency, the Norwegian Ministry of Petroleum and Energy via the Research Council of Norway, and the Norwegian Oil and Gas Association. The field work was part of the Norwegian monitoring programme for seabirds, which is funded by the Environmental Agency. We thank the large number of field workers that helped collecting the data at the study sites, in particular Per Anker-Nilssen, Kjell Einvik, Torgeir Nygård, and Tomas Aarvak, who assisted in many years. Great thanks are also due to ICES for permission to use data on saithe abundance provided by its Arctic Fisheries Working Group, to Geir Helge Systad who produced Fig. 1, and to 3 anonymous referees for very valuable comments to the manuscript. Access to the colonies was granted by permissions from the county governors of NordTrøndelag and Nordland and the Røst municipality administration. We are also indebted to the Norwegian Coastal Administration for allowing us to use the Sklinna lighthouse as a field station. All handling of shags was in accordance with Norwegian legislation.

\section{LITERATURE CITED}

Aebischer NJ (1986) Retrospective investigation of an ecological disaster in the shag, Phalacrocorax aristotelis: a general method based on long-term marking. J Anim Ecol 55:613-629

Anker-Nilssen T (2005) Sjøfugl og sei: predatorer og indikatorer i et klimaperspektiv. In: Svenning MA, Jonsson B (eds) Kystøkologi: Økosystemprosesser og menneskelig aktivitet. Norwegian Institute for Nature Research, NINA Temahefte 31:33-37

Anker-Nilssen T, Barrett RT, Bustnes JO, Erikstad KE and others (2006) The SEAPOP programme - a milestone for the mapping and monitoring of seabirds in Norway. Seabird Group Newsl 103:11-12

Bakken V, Runde O, Tjørve E (2003) Norsk Ringmerkningsatlas, Vol 1. Stavanger Museum, Stavanger (In Norwegian)

Barbraud C, Weimerskirch H (2006) Antarctic birds breed later in response to climate change. Proc Natl Acad Sci USA 103:6248-6251

Barrett RT (1991) Shags (Phalacrocorax aristotelis) as poten- 
tial samplers of juvenile saithe (Pollachius virens (L.)) stocks in northern Norway. Sarsia 76:153-156

Barrett RT, Lorentsen SH, Anker-Nilssen T (2006) The status of breeding seabirds in mainland Norway. Atl Seabirds 8:97-126

Burnham KP, Anderson DR (2002) Model selection and multimodel inference: a practical information-theoretic approach, 2nd edn. Springer, New York, NY

Burthe S, Daunt F, Butler A, Elston DA and others (2012) Phenological trends and trophic mismatch across multiple levels of a North Sea pelagic food web. Mar Ecol Prog Ser 454:119-133

- Bustnes JO, Anker-Nilssen T, Erikstad KE, Lorentsen SH, Systad GH (2013) Changes in the Norwegian breeding population of European shag correlate with forage fish and climate. Mar Ecol Prog Ser 489:235-244

Cairns DK (1987) Seabirds as indicators of marine food supplies. Biol Oceanogr 5:261-271

> Chastel O, Weimerskirch H, Jouventin P (1995) Influence of body condition on reproductive decision and reproductive success in the blue petrel. Auk 112:964-972

Cook RM, Heath MR (2005) The implications of warming climate for the management of North Sea demersal fisheries. ICES J Mar Sci 62:1322-1326

Cushing DH (1990) Plankton production and year-class strength in fish populations: an update of the match/mismatch hypothesis. Adv Mar Biol 26:249-263

> Daunt F, Afanasyev V, Silk JRD, Wanless S (2006) Extrinsic and intrinsic determinants of winter foraging and breeding phenology in temperate seabirds. Behav Ecol Sociobiol 59:381-388

Daunt F, Reed TE, Newell M, Burthe S, Phillips RA, Lewis S, Wanless S (2014) Longitudinal bio-logging reveals interplay between extrinsic and intrinsic carry-over effects in a long-lived vertebrate. Ecology 95:2077-2083

> Durant JM, Anker-Nilssen T, Hjermann DØ, Stenseth NC (2004a) Regime shifts in the breeding of an Atlantic puffin population. Ecol Lett 7:388-394

Durant JM, Stenseth NC, Anker-Nilssen T, Harris MP, Thompson PM, Wanless S (2004b) Marine birds and climate fluctuation in the North Atlantic. In: Stenseth NC, Ottersen G, Hurrell JW, Belgrano A (eds) Marine ecosystems and climate variation: the North Atlantic-a comparative perspective. Oxford University Press, New York, NY, p 95-105

> Durant JM, Hjermann DØ, Anker-Nilssen T, Beaugrand G, Mysterud A, Pettorelli N, Stenseth NC (2005) Timing and abundance as key mechanisms affecting trophic interactions in variable environments. Ecol Lett 8:952-958

> Durant JM, Hjermann DO, Ottersen G, Stenseth NC (2007) Climate and the match or mismatch between predator requirements and resource availability. Clim Res 33: 271-283

Edwards M, Richardson J (2004) Impact of climate change on marine pelagic phenology and trophic mismatch. Nature 430:881-884

Finney SK, Wanless S, Harris MP (1999) The effect of weather conditions on the feeding behaviour of a diving bird, the common guillemot Uria aalge. J Avian Biol 30:23-30

> Frederiksen M, Harris MP, Daunt F, Rothery P, Wanless S (2004) Scale-dependent climate signals drive breeding phenology of three seabird species. Glob Change Biol 10:1214-1221

Frederiksen M, Daunt F, Harris MP, Wanless S (2008) The demographic impact of extreme events: stochastic weather drives survival and population dynamics in a long-lived seabird. J Anim Ecol 77:1020-1029

Grémillet D, Chauvin C, Wilson RP, Le Maho Y, Wanless S (2005) Unusual feather structure allows partial plumage wettability in diving great cormorants Phalacrocorax carbo. J Avian Biol 36:57-63

Grémillet D, Pichegru L, Siorat F, Georges JY (2006) Conservation implications of the apparent mismatch between population dynamics and foraging effort in French northern gannets from the English Channel. Mar Ecol Prog Ser 319:15-25

> Hillersøy G, Lorentsen SH (2012) Annual variation in the diet of breeding European shag (Phalacrocorax aristotelis) in Central Norway. Waterbirds 35:420-429

> Homrum EI, Hansen B, Steingrund P, Hátún H (2012) Growth, maturation, diet and distribution of saithe (Pollachius virens) in Faroese waters (NE Atlantic). Mar Biol Res 8:246-254

Hurrell JW, Kushnir Y, Ottersen G, Visbeck M (2003) The North Atlantic Oscillation: climate significance and environmental impact. Geophys Monogr Ser 134. American Geophysical Union, Washington, DC

ICES (2013) Report of the Arctic Fisheries Working Group (AFWG), 18-24 April 2013, Copenhagen. ICES CM 2013/ACOM:05

IPCC (2007) Climate change 2007 synthesis report. Contribution of Working Groups I, II and III to the 4th assessment. Intergovernmental Panel on Climate Change, Geneva

Irons DB, Anker-Nilssen T, Gaston AJ, Byrd GV and others (2008) Fluctuations in circumpolar seabird populations linked to climate oscillations. Glob Change Biol 14: 1455-1463

Lorentsen SH, Christensen-Dalsgaard S (2009) The national monitoring programme for seabirds. Results up to and including the 2008 breeding season. NINA Report 439, Norwegian Institute for Nature Research, Trondheim

Mehl S, Zuykova NV, Drevetnyak KV (2011) Saithe. In: Jakobsen T, Ozhigin VK (eds) The Barents Sea: ecosystem, resources, management. Half a century of RussianNorwegian cooperation. Tapir Academic Press, Trondheim, p 281-291

Mehl S (2013) Northeast Arctic saithe. In: Bakketeig I, Gjøsæter $\mathrm{H}$, Hauge $\mathrm{H}$, Loeng $\mathrm{H}$, Sunnset $\mathrm{BH}$, Toft $\mathrm{K} \varnothing$ (eds) Havforskningsrapporten 2013. Fisken og havet, særnummer 1-2013, Institute of Marine Research, Bergen (in Norwegian)

> Moe B, Stempniewicz L, Jakubas D, Angelier F and others (2009) Climate change and phenological responses of two seabird species breeding in the high-Arctic. Mar Ecol Prog Ser 393:235-246

- Monaghan P, Uttley JD, Burns MD, Thaine C, Blackwood J (1989) The relationship between food supply, reproductive effort and breeding success in arctic terns Sterna paradisaea. J Anim Ecol 58:261-274

> Myksvoll MS, Erikstad KE, Barrett RT, Sandvik H, Vikebø F (2013) Climate-driven ichthyoplankton drift model predicts growth of top predator young. PLoS ONE 8:e79225

- Oro D, Hernández N, Jover L, Genovart M (2014) From recruitment to senescence: food shapes the age-dependent pattern of breeding performance in a long-lived bird. Ecology 95:446-457

> Ottersen G (2010) A digital temperature atlas for the Norwegian Sea. ICES J Mar Sci 67:1525-1537

Piatt JF, Harding AMA, Shultz M, Speckman SG, van Pelt 
TI, Drew GS, Kettle A (2007) Seabirds as indicators of marine food supplies: Cairns revisited. Mar Ecol Prog Ser 352:221-234

Rayner NA, Brohan P, Parker DE, Folland CK and others (2006) Improved analyses of changes and uncertainties in sea surface temperature measured in situ since the mid-nineteenth century: the HadSST2 dataset. J Clim 19: 446-469

Reed TE, Warzybok P, Wilson AJ, Bradley RW, Wanless S, Sydeman WJ (2009) Timing is everything: flexible phenology and shifting selection in a colonial seabird. J Anim Ecol 78:376-387

Sæther BE (1990) Age-specific variation in reproductive performance of birds. In: Power DM (ed) Current ornithology, Vol 7. Plenum Press, New York, NY, p 251-283

Sandvik H, Erikstad KE, Sæther BE (2012) Climate affects seabird population dynamics both via reproduction and adult survival. Mar Ecol Prog Ser 454:273-284

Sandvik H, Reiertsen TK, Erikstad KE, Anker-Nilssen T and others (2014) The decline of Norwegian kittiwake populations: modelling the role of ocean warming. Clim Res 60:91-102

SAS (2008) SAS/STAT 9.2 User's Guide. SAS Institute Inc., Cary, NC

Shultz MT, Piatt JF, Harding AMA, Kettle AB, van Pelt TI (2009) Timing in breeding and reproductive performance in murres and kittiwakes reflect mismatched seasonal prey dynamics. Mar Ecol Prog Ser 393:247-258

Smith TM, Reynolds RW, Peterson TC, Lawrimore J (2008) Improvements to NOAA's historical merged land-ocean surface temperature analysis (1880-2006). J Clim 21: 2283-2296

Stenseth NC, Ottersen G, Hurrell JW, Belgrano A (eds) (2004) Marine ecosystems and climate variation: the North Atlantic - a comparative perspective. Oxford University Press, New York, NY

Surman CA, Nicholson LW, Santora JA (2012) Effects of climate variability on breeding phenology and perform-

Editorial responsibility: Rory Wilson,

Swansea, UK ance of tropical seabirds in the eastern Indian Ocean. Mar Ecol Prog Ser 454:147-157

Svagelj WS, Quintana F (2011) Breeding performance of the Imperial shag (Phalacrocorax atriceps) in relation to year, laying date and nest location. Emu 111:162-165

Svagelj WS, Trivellini MM, Quintana F (2012) Parental investment theory nest defence by Imperial shags: effects of offspring number, offspring age, laying date and parent sex. Ethology 118:251-259

Sydeman WJ, Thompson SA, Kitaysky A (2012) Seabirds and climate change: roadmap for the future. Mar Ecol Prog Ser 454:107-117

Thomas CD, Cameron A, Bakkenes M, Green RE and others (2004) Extinction risk from climate change. Nature 427: $145-148$

Visbeck MH, Hurrell JW, Polvani L, Cullen HM (2001) The North Atlantic Oscillation: past, present, and future. Proc Natl Acad Sci USA 98:12876-12877

Visser ME, Both C (2005) Shifts in phenology due to global climate change: the need for a yardstick. Proc R Soc B 272:2561-2569

> Votier SC, Hatchwell BJ, Mears M, Birkhead TR (2009) Changes in the timing of egg-laying of a colonial seabird in relation to population size and environmental conditions. Mar Ecol Prog Ser 393:225-233

Walther GR, Post E, Convey P, Menzel A and others (2002) Ecological responses to recent climate change. Nature 416:389-395

Wanless S, Frederiksen M, Walton J, Harris MP (2009) Longterm changes in breeding phenology at two seabird colonies in the western North Sea. Ibis 151:274-285

> Wanless S, Harris MP, Lewis S, Frederiksen M, Murray S (2008) Later breeding in northern gannets in the eastern Atlantic. Mar Ecol Prog Ser 370:263-269

> Watanuki Y, Ito M, Deguchi T, Minobe S (2009) Climateforced seasonal mismatch between the hatching of rhinoceros auklets and the availability of anchovy. Mar Ecol Prog Ser 393:259-271

Submitted: December 19, 2013; Accepted: October 24, 2014 Proofs received from author(s): December 23, 2014 